\title{
Diagnostic Assessment of Adult Hydrocephalus Log compared to standard normal pressure hydrocephalus diagnostic tools
}

\author{
Ignacio Jusue-Torres ${ }^{1 *}$, Jennifer Lu', Jamie Robison', Jamie Hoffberger ${ }^{1}$, Jan Wemmer ${ }^{1}$, Abanti Sanyal², \\ Daniele Rigamonti ${ }^{1}$
}

From Hydrocephalus 2015

Banff, Canada. 18-21 September 2015

\section{Introduction}

Early treatment in Normal Pressure Hydrocephalus (NPH) yields better post-operative outcomes. Our current tests often fail to detect significant changes at early stages. We developed a new scoring system (LP log score) and sought a "proof of concept" that this tool is more sensitive in detecting clinical differences than the current ones.

\section{Methods}

We prospectively studied 62 consecutive new patients with suspected idiopathic NPH. Secondary, previously treated and obstructive cases were not included. We collected age, pre and post Lumbar Puncture (LP) Tinetti, Timed Up and Go (TUG), European NPH scale and LP log scores. LP $\log$ score is recorded at baseline and for 7 consecutive days after removing $40 \mathrm{cc}$ of CSF via LP. We studied the diagnostic accuracy of the tests for surgical indication.

\section{Results}

Median age at presentation was 76 (71-80) years old. TUG $(\mathrm{p}<0.0001)$ and Tinetti $(\mathrm{p}<0.0001)$ showed significant differences between presentation and post-LP scores. PostLP Log showed improvement in $90 \%$ of people with good baseline TUG, Tinetti and MCV tests and in $93 \%$ of people who did not show any pre-post LP change in TUG, Tinetti and MCV grade. Sensitivity, Specificity, and Accuracy to detect intention to treat when positive postLP improvements were respectively $4 \%$, $100 \%$ and $24 \%$ for TUG, $21 \%, 86 \%$, 34\% for Tinetti, $66 \%$, $29 \%$ and $58 \%$ for MCV grade and $98 \%, 33 \%$ and $85 \%$ for

\footnotetext{
* Correspondence: jusuet1@jhmi.edu

'Johns Hopkins University, School of Medicine, Department of Neurosurgery, USA

Full list of author information is available at the end of the article
}

LP log. PreLP-postLP TUG improvement and preLPpostLP Tinetti improvement were not associated with surgical indication $(\mathrm{p}>0.05)$. LP log improvement was associated with surgical indication OR: 24.5 95\% CI (2.4248.12) $(\mathrm{p}=0.007)$.

\section{Conclusions}

LP log showed a higher sensitivity and diagnostic accuracy detecting clinical differences in NPH than the current diagnostic approach. Our next step is to conduct a cross-validation analysis of the diagnostic and prognostic accuracy of this new tool.

\section{Authors' details}

'Johns Hopkins University, School of Medicine, Department of Neurosurgery, USA. ${ }^{2}$ Johns Hopkins University, Bloomberg School of Public Health, Department of Biostatistics, USA.

Published: 18 September 2015

\section{References}

1. Sankey EW, Jusue-Torres I, Elder BD, et al: Functional gait outcomes for idiopathic normal pressure hydrocephalus after primary endoscopic third ventriculostomy. J Clin Neurosci 2015, 1-6.

2. Moran D, Kosztowski TA, Jusue-Torres I, et al: Does CT wand guidance improve shunt placement in patients with hydrocephalus? Clin Neurol Neurosurg 2015, 132:26-30.

3. Jusue Torres I, Hoffberger JB, Rigamonti D: Complications Specific to Lumboperitoneal Shunt. Complications of CSF Shunting in Hydrocephalus. Springer; 2015, 203-11.

4. Elder BD, Sankey EW, Goodwin CR, Jusue-Torres I, Khattab MH, Rigamonti D: Outcomes and Experience with Lumbopleural Shunts in the Management of Idiopathic Intracranial Hypertension. World Neurosurg 2015, 1-6.

5. Jusué-Torres I, Hoffberger JB, Rigamonti D: Complications of Lumboperitoneal Shunts for Idiopathic Intracranial Hypertension. Cureus 2014.

6. Jusue Torres I, Hoffberger JB, Rigamonti D: Complications of Lumboperitoneal Shunts for Normal Pressure Hydrocephalus. Cureus 2014. 
7. Elder $B D$, Bankah $P$, Blitz $A M$, et al: Core imaging in adult hydrocephalus. Adult Hydrocephalus: Cambridge University Press;Rigamonti D 2014:110-20.

doi:10.1186/2045-8118-12-S1-044

Cite this article as: Jusue-Torres et al:: Diagnostic Assessment of Adult

Hydrocephalus Log compared to standard normal pressure

hydrocephalus diagnostic tools. Fluids and Barriers of the CNS 2015

12(Suppl 1):044.

Submit your next manuscript to BioMed Central and take full advantage of:

- Convenient online submission

- Thorough peer review

- No space constraints or color figure charges

- Immediate publication on acceptance

- Inclusion in PubMed, CAS, Scopus and Google Scholar

- Research which is freely available for redistribution

Submit your manuscript at 